\title{
MADRID EN LOS ARTÍCULOS SATÍRICOS COSTUMBRISTAS DE MODESTO LAFUENTE
}

\author{
Mònica FUERTES ARBOIX \\ Coe College
}

\section{RESUMEN}

El Madrid de la primera mitad del siglo es un lugar caótico en donde se desarrollan los más importantes acontecimientos de la vida política, cultural y económica de España. La capital se desarrolla y crece de la mano de miles de personas que viven con la esperanza de subirse al carro del progreso y transformar su realidad. Madrid será el escenario de infinitos cambios que muchos escritores plasmarán en los periódicos, cada vez más abundantes y poderosos, del momento. De entre estos observadores cabe destacar s Modesto Lafuente, crítico feroz de la realidad social y política de España que a través de su periódico Fray Gerundio (1837-1842), supo plasmar los más satíricos cuadros de los habitantes de la ciudad, desde el político irresponsable a las viudas y huérfanos que sobreviven pos sus calles. Este artículo se centra en este escritor y su exitoso periódico y en el uso que hace de Madrid como escenario de sus crónicas y críticas sociales.

Palabras clave: Modesto Lafuente, Fray Gerundio, Madrid, 1837-1842, ciudad moderna, crítica social, sátira costumbrista, crítica política.

\section{ABSTRACT}

The city of Madrid in the first half of the 19th century is a chaotic place where the most important political, cultural, and economic events of the daily life take place. Life in the city grows and develops thanks to the thousands of people who hope to have a taste of the progress going on in the city, and have the opportunity to change their reality. Madrid will be the scenario of infinite changes that many writers want to capture in the growing periodicals of the time. Among these writers, Modesto Lafuente stands out, a ferocious critic of the daily social and political reality of the Spain at the time. Lafuente published the satirical newspaper Fray Gerundio 
(1837-1842), where he depictured the most satirical descriptions of the inhabitants of the city, including the irresponsible politician and the life of widows and orphans who survive in the streets. This article focuses in this particular author and his successful satirical newspaper and in the city of Madrid as scenario of his chronicles and social criticism.

Key words: Modesto Lafuente, Fray Gerundio, Madrid, 1837-1842, modern city, social criticism, satire of customs and mores, political criticism.

El crecimiento de las ciudades en la primera mitad del siglo XIX trae como consecuencia una serie de transformaciones urbanísticas que repercuten en la sociedad y en la economía de la urbe. Quizá la más evidente sea la transformación social que va indisolublemente unida al desarrollo de la ciudad. No hace falta más que mirar hoy en día a nuestro alrededor y fijarnos en cómo las recientes oleadas de inmigrantes han transformado los barrios que configuran el mapa urbanístico de cualquier ciudad española como Madrid o Barcelona, por ejemplo. Pero la ciudad también cambia porque debe adaptarse a la nueva sociedad que crece dentro de sus límites, y a veces fuera de ellos, fruto de las relaciones entre sus habitantes. La ciudad guarda en ella el futuro y la esperanza pero también la memoria de lo que fue y de las gentes que vivieron en ella. Nombres, plazas, hospitales, bibliotecas, universidades..., pequeños microcosmos sociales que mantienen una relación directa con la ciudad a través de su historia y su presente.

Cities brought together energy, information, and human and financial capital in the critical mass needed for social transformation. New forms of transportation, communication, employment, family life, governance, and leisure within Europe, which signaled the change from the world of the mid-eighteenth century to that of the twentieth, were also closely linked to development (Lees and Hollen, 2007:1)

Estudiar el desarrollo de las ciudades abre la ventana al estudio de muchos aspectos de vital importancia para la historia de su progreso, sobre todo en la primera mitad del siglo XIX, cuando las ciudades empiezan a rivalizar por adquirir la calificación de ciudad moderna. En este artículo vamos a centrarnos en el estudio del Madrid de la primera mitad del siglo XIX de la mano de uno de sus críticos más feroces, Modesto Lafuente. Paradójicamente, Lafuente no centra sus artículos en plasmar el desarrollo urbanístico de Madrid, ciudad que le ha de dar fama inmediata, sino que Madrid es el escenario en que sus habitantes viven y se relacionan guiados por unos dirigentes que fracasan constantemente en sus decisiones llevando a la ciudad, y por extensión al país, a la ruina. Lafuente es, pues, el cronista social del Madrid político desde 
1837 hasta 1841 en las páginas de su popular semanario Fray Gerundio ${ }^{1}$. Como advierten Lees y Hollen, las ciudades en el siglo XIX son centros en los que se desarrolla la modernidad entendida como los cambios que se producen al pasar de una sociedad centrada en el antiguo régimen a una ciudad democrática. Pero el caso de Madrid, y en verdad de toda España, no es así. Si la muerte y el hambre son las características principales del Madrid de principios de siglo, seguirá siendo así hasta una vez iniciada la liberalización del país ya que «el fin del Antiguo Régimen y los comienzos del Estado Liberal no fueron en Madrid, ni en España, obra de una próspera burguesía mercantil e industrial sino más bien resultado de una ruina económica que arrastró en su estela una quiebra política» (Julià, 1994: 265). Las reformas económicas que posteriormente llevó a cabo Mendizábal con la desamortización de las propiedades eclesiásticas no tuvieron el resultado que se esperaba y es algo de lo que se hace eco Fray Gerundio. En su camino a Madrid desde León observa éste el lamentable estado de los conventos en Salamanca y el hambre que pasan los que se encuentra en su camino, como los que se encargan de pasar por un miserable sueldo a las personas de orilla a orilla del río Adaja, a los que Fray Gerundio califica de puentes de carne ya que "por miserables dos cuartos tendréis el gusto de montar en un hombre, como montó mi lego; y después desafiad a los estrangeros a ver si con todo su progreso y sus artes y su industria han llegado ellos a tener puentes racionales como tenemos nosotros en Castilla» (Fray Gerundio: 1840, Vol. III, 18). Hambre y miseria que le seguirán hasta su entrada en la corte el 5 de julio de 1838. Una vez instalado en Madrid y empezando su tarea de periodista sigue escribiendo sátiras políticas como observador implacable de las sesiones de las Cortes. De estas observaciones se advierte el estado lamentable en el que se encuentra Madrid, pero sobre todo sus gentes. Por extensión, Lafuente quiere señalar el lamentable estado en que encuentra el país en general. Para él, no cabe duda, los culpables son los políticos. Madrid es el escenario en el que se juega el futuro de España. Madrid es un no-lugar en el que todas las miserias sociales tienen cabida. Es además, un escenario en el que se mal practica la política. Son escasas las descripciones de las calles y edificios, comparadas con las de su contemporáneo Mesonero Romanos. Y eso es así porque a Lafuente no le interesa la pincelada segura y mimética de la narración costumbrista, sino que Madrid es el marco

1. Hay que precisar que la publicación de Fray Gerundio empieza en León en 1837, aunque los artículos hacen referencia a las decisiones de los políticos en Madrid y, sobre todo, a la guerra civil que asolaba al país y las consecuencias económicas que tuvieron en la sociedad. Tras el éxito obtenido casi de inmediato, decide trasladarse a la capital para seguir más de cerca y sin demoras las decisiones políticas de los gobernantes. 
que circunscribe las malogradas decisiones políticas y económicas que afectan no sólo a la capital sino a todo el país. Madrid es el centro del desastre desde el cual el escritor puede relatar las consecuencias que esas medidas tomadas por el gobierno tienen en la sociedad. Hay que recordar que desde que inicia la publicación del Fray Gerundio en 1837 el país está en guerra, una incomprensible y larga guerra que está arruinando aún más a España y que tiene terribles consecuencias para la población. De hecho el tema de la guerra será constantemente amonestado porque aumenta la problemática social del país como el crecimiento incesante de viudas y huérfanos que no tienen acomodo en el Madrid de esos años. Esto evidencia la falta de infraestructura social de la que adolece la capital. En uno de sus mordaces artículos incita a los políticos a que sean ellos los que se maten,

Estoy temiendo que tanta ilustración ha de venir a parar en suicidarnos todos, y en verdad que puede que fuera el único medio de acabar con esta pícara guerra, este pícaro cáncer que nos va royendo a todos insensiblemente las entrañas. Señores, animémonos; yo soy uno de tantos: les doy a uds. palabra, a fé de Fr. Gerundio, que lo mismo será verles a uds. todos estirar la pata, no tardo medio siglo en dejarme morir [...] Efectivamente deben uds. irse suicidando. La gente del movimiento, y los hombres de letras ya han empezado a dar ejemplo. El otro día un maestro de baile se tiró en el estanque del Retiro y habiendo sido feliz en la ejecución de una variación que ensayaba por primera vez, tuvo la fortuna de acertar a ahogarse (Fray Gerundio: 1840, Vol. III, 55)

Todos los temas de la realidad contemporánea tienen cabida en el Fray Gerundio. La sátira, esa anárquica convención literaria en la que todo vale, está presente desde el principio al fin, empezando por la forma y estructura del semanario ${ }^{2}$, al contenido de los temas que trata: literarios, de política y de costumbres. La sátira lo abarca todo: nada está mal, nada sobra, nada es excesivo o escaso, de mal gusto o extremadamente erudito. Se trata de destruir con la palabra el presente para ofrecer una imagen de la realidad mucho más poderosa y real. Dentro de este aparente mundo anárquico se pueden distinguir, sin embargo, algunos de los temas que reiteradamente aparecen el semanario como la política, la guerra civil, que mencionábamos anteriormente, la consecuente crisis económica, la libertad de imprenta y la relación con la prensa contemporánea. Además, estos temas tratan de manera directa

2. Los artículos al principio de la publicación adoptan la forma de los sermones, posteriormente siguen la estructura de artículos periodísticos a los que Lafuente llamará capilladas haciendo clara referencia al golpe dado con la capilla del hábito de los monjes. 
o indirecta las consecuencias sociales que su larga duración tienen en la sociedad española.

El nuevo gobierno que se instituyó en 1837 temeroso de las consecuencias del motín de la Granja no quiso restablecer la Constitución de Cádiz que había prometido. La prensa se enfrentó al gobierno y se temían nuevas conspiraciones organizadas en sociedades secretas y en los periódicos. Lafuente expresa su desconfianza en el Gobierno de Calatrava en una de las primeras capilladas de abril de 1837, «Fray Gerundio y un comerciante», en la que éste discute con un comerciante sobre unos paquetes de garantías del gobierno que éste le intenta vender,

Pues escusa V. de desempaquetar, porque me consta que es género falso. - $\mathrm{Si}$ quiere V. buenos antecedentes también los traigo. -Políticos, supongo. -Si señor, políticos. -Retírelos V., que esos ya no rigen. Hay también buenos principios, ¿quiere V. alguno? -Ya me contentaría yo con tener seguro un simple puchero, cuando mas meterme ahora en principios ni postres. Si son principios políticos también, Señor. [...] Quiere V. alguna tabla de derechos? ¿De derechos de puertas? -No señor, de derechos del hombre. Estos son arreglados, pero es todavía género de contrabando; y me cuesta traerlos embutidos en sociedades secretas debajo de esos periódicos de la oposición, y bien liados en cinta de teorías: ¿quiere V también teorías sueltas? (Fray Gerundio: 1840, vol. I, 35-36).

Según el protagonista, los planes de desamortización de Mendizábal fueron una estafa y nunca se solucionó el problema del empréstito dentro y fuera de España. Lo que más molesta a Fray Gerundio es que el gobierno siga prometiendo soluciones a corto plazo que nunca se llegan a cumplir. Interesante y divertida es la crítica que hace de las manifestaciones a favor de la Constitución del año 12 y del año 37 y de los diferentes grupos políticos que abogan por imponer su ideología y programa político.

¿Qué voces son esas que se oyen a lo lejos, y cuya confusa mezcla no deja percibir más que el eco del final «OOOn?»-Esos son algunos que gritan viva la ConstituciON: escuche V. verá como se oye por lo bajo que dicen entre dientes; del año 12 , y piden lo que es justo. $-i$ Con que piden lo que es justo? Cómo se engaña V., amigo mío lo que gritan es viva la ConstituciON, poco después añaden, reformada; y está demostrado ya que es la que conviene. Tan engañados estais uno como otro: os ilusionan los deseos; lo que dicen es: que progresa la facciON! Que nos vende algún bribON! Acabemos con la facciON! Y en verdad que es lo que importa (Fray Gerundio: 1840, vol. I, 105).

Fray Gerundio es de la opinión de que antes de aprobar la Constitución hay problemas más urgentes como el de la guerra. Además, como los políticos no mantienen las promesas, una vez en el poder hacen y deshacen sus planes según les parece mejor, como el de añadir decretos a la Constitución de 1812 
para matizar su contenido y evitar enfrentamientos con los otros partidos políticos y con la prensa. «En vista pues de tan constante mania de apendizarnos o adicionarnos cuanto a decreto huele, yo Fr. Gerundio, me veo en la necesidad de hacer la siguiente proposición a la Academia española: Pido que el adagio español que dice: no hay sábado sin sol, ni doncella sin amor, ni vieja sin dolor, se añada, ni decreto sin apéndice» (Fray Gerundio: 1840, vol. II, 10)

A Fray Gerundio le irrita la división política entre los miembros de los partidos liberales porque pone trabas constantes a proyectos importantes para el bienestar de la nación, como el fin de la guerra civil o la implantación de programas económicos que realmente funcionen y reformen la economía. «yo confío, hermano Pelegrín, en que se han de hermanar los bandos liberales en rededor de este pendón de la libertad; casi creo que está hecha la reconciliación» (Fray Gerundio: 1840, vol. II, 140). Pero desde los periódicos se alimenta el malestar y la enemistad entre los partidos políticos y son imposibles la hermandad y la paz en el gobierno. Fray Gerundio echa la culpa también de este rencor y pugna constante entre partidos a los políticos exiliados que volvieron tras la muerte del Rey. Se esperaba de ellos que trajeran grandes ideas y mejoras económicas, pero fueron los principales iniciadores de las escisiones entre los partidos liberales, sobre todo entre los exaltados y los moderados. Así retrata en unos versos sarcásticos la decepción que supuso su vuelta:

¿Y son estos los hombres

que TAN GRANDES, TAN GRANDES nos pintaban,

y cuyos huecos nombres

en Londres y París tanto sonaban,

los sabios diplomáticos profundos,

políticos GIGANTES,

que con hombros de Talantes

pretenden sustentar entrambos mundos?

Ay! Qué grandazos

serían allá!

ay que pequeños

van siendo acá!

Gran Dieu, qu'ils sont petits!

petits, petits, oui petits, tout petits. (Fray Gerundio: 1840, vol. I, 178-179)

Como vemos, la política empapa todos los artículos de esta publicación. Cada pequeño acontecimiento, noticia en la prensa o sesión en las Cortes encuentra su sitio en las páginas del Fray Gerundio, y los ejemplos que aquí incluyo son una muestra de sus observaciones sobre la vida política española. Aunque Lafuente simpatiza con el grupo liberal progresista, no se rige por 
una ideología política partidista. Entiende que el problema de España no se resolverá mientras los partidos políticos no lleguen a un acuerdo y dejen de provocar altercados y levantamientos cada vez que accede al poder un grupo político determinado. El entendimiento, a veces, sólo es posible manteniendo una postura moderada que intente aproximar los intereses de cada grupo. No es de extrañar que en su madurez Lafuente fuera diputado por el partido moderado de O’Donnell ya que, según su experiencia como observador político desde Fray Gerundio, cuando uno de los grupos liberales formaba gabinete volvían a surgir viejas rencillas y odios que dificultaban la viabilidad de los planes políticos.

Otro de los problemas que tuvieron que afrontar los gobiernos que se constituyeron durante este período, fue el de acabar la guerra civil entre carlistas y liberales iniciada a la muerte del rey en 1833. Este es uno de los temas que más preocupa a Lafuente, sobre todo porque del fin de la guerra depende en gran parte la regeneración económica del país. Los moderados trataron de solucionar la cuestión de la sucesión al trono mediante pactos para así evitar la confrontación militar, pero los liberales querían solucionar el conflicto en el campo de batalla.

De hecho, a Fray Gerundio le es igual cómo se solucione el conflicto bélico; lo importante es que se ponga punto final a una guerra que debería haber terminado a poco de empezar, si tenemos en cuenta que las potencias que firmaron la Cuádruple Alianza -Inglaterra, Francia, España y Portugalen 1834 se comprometieron a defenderse y auxiliarse mutuamente contra el absolutismo ${ }^{3}$. Como es de suponer, los objetivos de la ira de Fray Gerundio son el Infante Don Carlos y los militares que apoyan su causa.

3. La situación la describe muy bien Fray Gerundio en una partida de cartas entre Doña Hispania, Doña Francesina, Doña Britania, el Pretendiente de Doña Hispania y D. Portugalito. En esta partida Doña Hispania siempre pierde porque no se acuerda de jugar al rocambor; unos mirones que están viendo la partida le aconsejan miles de cosas diferentes, comprometiéndola y descubriendo su juego. "El resultado era que Doña Hispania se iba quedando sin cuartos, porque el caballero Pretendiente, aunque se decía Pretendiente de la señora, no trataba más que de chuparla lo que podía. No era extraño, porque para entrar a jugar había tenido que empeñarse mucho, pidiendo prestado a sus amigas Doña Rusita, Doña Holandita, y otras. ¡Mire V. qué méritos de Pretendiente! Estar obsequiando hasta con bajeza a las damas más enemigas de aquella cuya quedando sin cuartos, porque el caballero Pretendiente, aunque se decía Pretendiente de la señora, no trataba más que de chuparla lo que podía. No era extraño, porque para entrar a jugar había tenido que empeñarse mucho, pidiendo prestado a sus amigas Doña Rusita, Doña Holandita, y otras. ¡Mire V. qué méritos de Pretendiente! Estar obsequiando hasta con bajeza a las damas más enemigas de aquella cuya mano pretende!» (Fray Gerundio: 1840, vol. II, 39-40). 
Sin embargo, al tratar el tema de la guerra es donde se descubre el más puro y enternecedor sentimiento de Fray Gerundio. Si con la sátira fustiga el alma despertando con la risa la conciencia del lector, con la sufrida descripción de la Navidad en 1837 suscita la tristeza del recuerdo de lo que ya nunca ha de volver. Así, descubrimos una vez más el Lafuente social preocupado por las consecuencias trágicas de estos conflictos en Madrid y en España.

¿Qué familia habrá que en esta noche mas que en cualquiera otra, que en esta noche que la religión, la educación, la costumbre consagran diez y nueve siglos há el placer de reunirse los parientes y amigos más allegados en derredor de una mesa, ¿qué familia habrá que no llore al triste y desconsolado recuerdo del hijo que pereció en el campo de batalla, del hermano que asesinó bárbaramente la facción, del padre que gime en la miseria y la desnudez prisionero de los vándalos, del esposo que está padeciendo en un hospital militar, del amante que perdió la pierna o el brazo, del amigo que hacía las delicias de la familia, y hoy corre los riesgos, de la guerra, de la fortuna que le arrebataron los bandidos de la falta de pagas que constituían su único haber, y hoy no la permite poner una triste ensalada con que celebrar la noche buena, que quizá no la ha dejado una pobre cama en que dormir? (Fray Gerundio: 1840, vol. II, 175)

No exagera al tratar este tema tan preocupante. Sólo hay que pensar por un momento en los ochenta y tres grabados que hizo Goya sobre los desastres de la guerra entre 1810 y 1820. Como él, Fray Gerundio no está tratando de hablar de la guerra como si fuera un espectáculo. Los dos pretenden indignar y concienciar al público y lo hacen de la mejor manera que saben: Goya mostrando el sufrimiento para conmover al espectador, Fray Gerundio sintetizando en palabras el dolor de un conflicto absurdo que está arruinando al país. Con la sátira Lafuente intenta dotar a las palabras de nueva significación, crear nuevos conceptos para señalar la absurda realidad, y denunciar al lector las cosas que ocurren en su país.

Incluso una vez conseguida la paz, un exigente e insatisfecho Fray Gerundio recuerda que otros problemas siguen sin solucionarse. Lo cierto es que el convenio de paz entre Espartero y Maroto supuso una serie de concesiones que sorprendieron negativamente a los liberales más exaltados, quienes manifestaron su malestar en el Parlamento y en la prensa. La prerrogativa que produjo más malestar fue la concesión de los fueros a las Provincias Vascongadas y Navarra y provocó una división entre los partidarios y los adversarios de los fueros que finalmente terminó con la disolución de las Cortes el 18 de noviembre de 1839.

Pero la deseada paz trajo consigo consecuencias que incrementaron la caótica situación política de España. No le faltaron asuntos a Fray Gerundio 
para sus capilladas pues la guerra continuó en Levante hasta mayo de 1840 y no desaparecieron los numerosos problemas que aquejaban al país como la grave crisis económica.

Como mencionábamos al principio de este artículo, la reforma económica propuesta por Mendizábal se consideró como la panacea ideal que iba a solucionar todos los problemas de empréstitos nacionales y extranjeros de España. El voto de confianza de las Cortes otorgando a Mendizábal plena libertad de acción resultó un fiasco y la prensa y los políticos de la oposición se indignaron. La desamortización de los bienes de la Iglesia fortaleció sobre todo la causa liberal: los bienes se repartieron entre los liberales que ya gozaban de una posición económica privilegiada y entre los que el afán de conservar el capital expoliado les hizo prometer fidelidad absoluta al régimen que se lo concedió. Las víctimas de aquel proyecto fracasado fueron los frailes y las monjas que se vieron en la calle de un día para otro. Se les prometió una renta de cinco reales que nunca llegó y las ciudades no contaban con las infraestructuras necesarias para hacerse cargo del gran alud de exclaustrados. Además, había en ellas una multitud de viudas, cesantes y jubilados sin recursos económicos y empujados a la mendicidad. «Por qué no ha de haber, señores, emplaeti boniti, barati, que ni coman, ni beban, ni gasten zapati? Y sino, verán uds. que bien suena al oido: cesanti e jubilati boniti barati. Mejor suena aún, dijo otro excelencia: esclaustrati boniti, barati. Y mejor, replicó el primero: monjiti e viudite bonite barate» (Fray Gerundio: 1840, vol. III, 99).

Fray Gerundio usa la sátira para concienciar a sus lectores sobre la vida de Madrid. Dice que desde que empezó la publicación del semanario su casa parece un tribunal de apelaciones pues todo el mundo viene a contarle sus problemas. De esta manera, se hace propaganda y aumenta la popularidad de su semanario. «Padre Fr. Gerundio, diga V. algo por Dios sobre el hambre que estamos pasando yo y mis seis chiquillos al cabo de un año que hace que no cobro un cuarto, me dice llorando una señora viuda, demacrada, y llena de ayes y dolencias» (Fray Gerundio: 1840, vol. I, 114). La exageración es una manera de resaltar la realidad y de captar la atención del lector, « ¡Cuidado que no se puede dar un paso sin tropezar con un pobre! iJesús que horror! Parece que los han sembrado. No bien ha salido uno de casa, impregnado acaso de ideas de felicidad, si acaba de leer un decreto de reforma, o el manifiesto de un ministro, cuando se le presenta a la punta de la nariz un sombrero cotroso, acompañado de un por amor de Dios [...]» (Fray Gerundio: 1840, vol. II, 69). Con aguda visión y parodiando a Horacio, escribe: 
Creedme, Pisones; los pueblos son momias. Su único clamor es paz y pan: sus deseos se limitan a que les dejen comer un pedazo de pan en paz: sus ideas dominantes paz y un zoquete de pan por activa, y un mendrugo de paz y pan por pasiva, y paz por participio, y pan por futuro en rus. El partido con quien tienen mas simpatías es el que les eche menos contribuciones: el mejor gobierno para ellos el que menos les adjetive, y la mejores Cortes las que gerundien menos (Fray Gerundio: 1840, vol. III, 14).

Esta mezcla de sátira y de sentido de la realidad española es, creo, uno de los factores del éxito del semanario. Fray Gerundio informa sobre la vida contemporánea en todas sus facetas: lúdica, trágica, sorprendente e ilógica; el prisma con que enfoca los problemas es siempre distinto y audaz. Fray Gerundio quiere asombrar y concienciar al lector que está cómodamente leyendo sus noticias; un lector que, según el mismo Fray Gerundio, pertenece a todos los ámbitos de la sociedad. Ahí reside el éxito, en ser una publicación tan atractiva tanto para el abogado como para el panadero que lo lee en voz alta. Fray Gerundio trata de política contemporánea y de las consecuencias para la sociedad de las decisiones que se toman en las Cortes, algo que atañe a toda la población en mayor o menor grado. Los pobres en Madrid son una realidad tangible con la que los lectores se identifican, asimismo los exclaustrados, las viudas y los huérfanos. Además, el estilo directo, las imágenes conmovedoras, el lenguaje sencillo a la vez que espontáneo, con que relata la vida tal y como la ve aumentan su éxito,

Efectivamente, las viudas son las tórtolas de la sociedad humana: las sombras animadas del gran cuadro social, son el vocativo caret de los matrimonios; son el pretérito perfecto del verbo conyugar; son como las judías en las huertas, que mientras tienen un apoyo o estacón a que asirse, levantan en derredor de él su lozano tallo, pero una vez que les falte, le doblan humilde y mustio hasta el suelo, y es no pocas veces cruelmente hollado por el brusco pie del jardinero, o por la inconsiderada planta de cualquier transeúnte (Fray Gerundio: 1840, vol. III, 119).

Cansado de leer lástimas, y asaltándome de nuevo la imagen del manto del albornoz, no quise por aquel día abrir mas correo, no acertando a concebir como la España del correo de Fr. Gerundio fuese la misma España que acababa de ver en el Prado. Y es que esta España que nos parece una sola deben ser dos Españas distintas. Una rica y suntuosa, que es la España de Toreno y otros pocos, y otra escuálida y tísica que es la España del resto de los españoles. (Fray Gerundio: 1840, vol. IX, 195).

Para terminar me gustaría mencionar un pequeño artículo que dedica a los principales responsables de la venta de prensa periódica por las calles de Madrid. En este artículo se ve claramente la preocupación por la sociedad madrileña de su tiempo. Me refiero a los ciegos, quienes como consecuencia de 
la Real orden publicada en junio de 1839 se ven privados de hacer el único trabajo que les era permitido y del que eran dueños exclusivos. «La hermandad de los ciegos de Madrid, - «sort of masonic fraternity amid the powers of darkness»- muere como institución, víctima de la evolución de la sociedad y de la organización del comercio y de la industria, del progreso de las técnicas de la información y, en menor grado, de la naturaleza de sus actividades, consideradas peligrosas para el poder y para las instituciones». (Botrel, 1993: 94). Tirabeque se pregunta por qué a las rabaneras y todos los vendedores les está permitido vocear por las calles y plazas de la Villa «para publicar sus géneros de comercio e industria» (Fray Gerundio: 1840, vol. XI, 204), y en cambio los escritores no pueden vender sus obras por medio de «los pobrecitos ciegos que no tienen otro modo de ganarse la vida, los prenden y los meten en calabozos, y los tienen días y más días, o los mandan de justicia en justicia a cincuenta o cien leguas sin más socorro que el de Dios, nada más que porque publican por la calle un periódico o un impreso cualquiera». (Fray Gerundio: 1840, vol. XI, 204). Opina Tirabeque que el gobierno debería procurar que no se publicasen anuncios en contra de la moral porque confía en el buen criterio del público para saber discernir el buen periódico del malo como el Eco de la Milicia Nacional o El Huracán. También se queja Fray Gerundio de que el gobierno encarcele a los ciegos sin proporcionarles otra manera de ganarse la vida y añade indignado que «bochornoso es, Pelegrín, e ignominioso para nuestra patria, que en todas las naciones haya de haber establecimientos de asilo y educación para los ciegos, menos en este nuestro siempre mal gobernado país.» (Fray Gerundio: 1840, vol. XI, 205) La capillada termina con una mención a la ceguera de los ministros y considera Tirabeque que a los nueve mil ciegos que se cuentan en la costa del Mediterráneo hay que añadir «otros ciento y tantos» porque sólo en un país de ciegos puede suceder que se prive a los escritores de lo que no se priva a las rabaneras y se trate tan mal a los ciegos.

$\mathrm{Si}$, al principio de su publicación, Fray Gerundio repite en numerosas ocasiones su imparcialidad política y la gran consideración que tiene a sus hermanos periodistas, vemos cómo, a medida que la situación política se complica y se diversifica la prensa, no puede permanecer callado y comparte, aunque no quiera, su ideología con el público. La imagen de escritor liberal progresista que ofrecía Lafuente desde León se va matizando con los años y, aunque continua defendiendo el constitucionalismo, sus simpatías se decantan por los moderados y así se mantendrá hasta el final del semanario y de la vida del escritor. 
Las aventuras de Fray Gerundio no terminaron aquí. Recordemos que Lafuente publicó bajo el título de Fray Gerundio. Era segunda (1843-1844), más artículos periodísticos con Fray Gerundio y Tirabeque como protagonistas. Los mismos personajes, además, siguen sus aventuras en el Teatro social del siglo XIX (Madrid 1845-1846), en el Viage aerostático de Fr. Gerundio y Tirabeque: capricho gerundiano: en que se dá cuenta de la espedición aérea que verificaron Fr. Gerundio y su lego en el globo de Mr. Arban y en su compañía, la tarde de I de noviembre de 1847 (1847), La revista Europea (1848-1849) y los Viajes de Fray Gerundio por Francia, Bélgica, Holanda y orillas del Rhin (1851). Suspender la publicación no significó dejar de lado a Fray Gerundio y Tirabeque, todo lo contrario. Aprovechando la popularidad que le dieron estos dos entrañables personajes Lafuente continuó publicando libros con ellos como protagonistas. Incluso él firmaba las colaboraciones que hiciera en otros periódicos, con el nombre de Fray Gerundio, que ya no había de abandonar hasta su muerte en 1866.

Fray Gerundio tuvo una influencia extraordinaria en el periodismo de su tiempo y tras él aparecieron periódicos y revistas como Fray Junípero (Madrid 1840), Fray Gerundio (Sevilla 1843), Fray Supino Claridades y Fray Tinieblas, ambos publicados en 1855. Las ilustraciones que muestran a los personajes de Fray Junípero y su lego son muy similares a las de Fray Gerundio y Tirabeque, sin duda alguna para identificar el carácter satírico de la publicación y aprovechar el éxito del semanario de Lafuente para hacerse publicidad.

Como hemos visto la ciudad para Lafuente es un lugar abandonado por los políticos en la que no ocurren grandes cambios urbanísticos. No hay descripciones detalladas de calles o edificios si no es para destacar el abandono en que se encuentran. A Lafuente le interesa la política, pero sobre todo las consecuencias sociales que su mala práctica tiene en la población de Madrid. Al contrario de otros costumbristas como Mesonero Romanos que se proponen «convertir en modelo a las demás poblaciones para que sirva a un tiempo de estímulo y gloria de nuestra patria» (Julià: 1994, 287). Algo que no está en los planes de Lafuente concentrado en mostrar la realidad tal y como es a través del costumbrismo satírico, para él el único medio eficaz de enseñar Madrid en toda su complejidad y caos social.

\section{BIBLIOGRAFÍA}

BOTREL, Jean François. Libros, prensa y lectura en la España del siglo XIX. Madrid, Fundación Germán Sánchez Ruipérez, 1993.

Julié, Santos, David Ringrose y Cristina Segura. Madrid, historia de una capital. Madrid, Alianza editorial, 1994 
Lafuente y Zamalloa, Modesto. Fray Gerundio. Periódico satírico de política y costumbres, Madrid, Imprenta de Mellado, segunda edición, 15 volúmenes, 1840.

LeES, Andrew and Lynn Hollen LeEs, Cities and the Making of Modern Europe, 1750-1914. Cambridge, Cambridge University Press, 2007.

Fecha de recepción: 12-12-2011

Fecha de aceptación: 15-5-2012 